\title{
Cuando el médico es el paciente
}

\section{When the doctor is the patient}

Pedro Félix Albújar-Baca ${ }^{\dagger}$

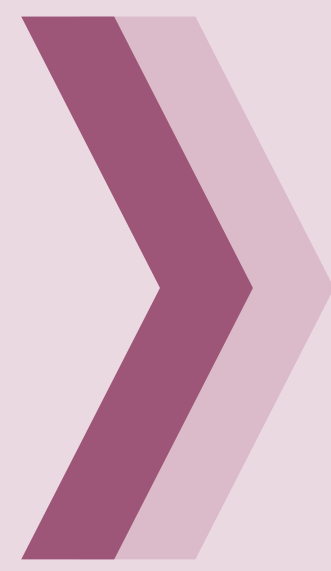

\section{RESUMEN}

Se aborda algunos aspectos de los médicos cuando se convierten en pacientes, como su resistencia para aceptar el cambio de rol, el burocratismo e ineficiencias de la atención sanitaria, el comportamiento de los médicos tratantes con el paciente médico, la relación médico-paciente después de la recuperación y la responsabilidad del médico en el autocuidado de su salud.

Palabras clave: relaciones médico-paciente; médicos; atención al paciente; pacientes

\section{INTRODUCCIÓN}

Para los médicos es muy difícil enfrentar la enfermedad en la condición de pacientes. El temor al dolor, al riesgo de la incapacidad o la muerte nos coloca en la misma situación de quienes se sientan frente a nosotros. Súbitamente nos convertimos en uno más de ellos, los pacientes, y nos cuesta aceptar el cambio de identidad profesional. Entre las profesiones, parece irónico que el financista quiebre, que el abogado sea enjuiciado o que el médico sea el paciente.

\section{¿ACEPTA EL MÉDICO LA POSIBILIDAD DE ENFERMAR?}

Frente a la posibilidad de enfermar, los médicos reaccionan no pocas veces con un sentimiento de
1 Médico anatomopatólogo

Exdecano de la Facultad de Medicina, Universidad Nacional de Trujillo. Académico Emérito de la Academia Nacional de Medicina.

\begin{abstract}
This article discusses some aspects of physicians when they become patients, as resistance to accept the new role, bureaucracy and inefficiencies of the sanitary system, the attending physician and the ill doctor, the doctor-patient relationship after recovery, and the physician's own health care responsibility.
\end{abstract}

KEY WORDs: physician-patient relations; doctor; physicians; patient care; patients invulnerabilidad. Con un pensamiento tipo mágico atribuyen a la bata blanca una suerte de escudo protector contra las enfermedades. La soberbia del sano, esa presunción que la enfermedad solo afecta a los demás, parece estar muy arraigada en la profesión médica. El imaginario de la sociedad también participa del mito al atribuir a los médicos una suerte de exención.

\section{¿SE PREOCUPAN LOS MÉDICOS POR SU SALUD?}

Con frecuencia los médicos subestiman o trivializan los síntomas de sus enfermedades y adoptan para sí conductas distintas de las aconsejadas a los pacientes. Un estudio del Colegio de Médicos de Barcelona reveló la despreocupación generalizada 
del colectivo médico por su salud. Ante un problema de su salud, optan por la automedicación; y si consultan, lo hacen de manera informal, sea por teléfono, en el pasillo del hospital y con referencia a un tercero. ${ }^{1}$

Cuando el médico enferma y se ve obligado a aceptar la condición de paciente, experimenta una serie de transformaciones de orden personal, profesional y asistencial. Ante el diagnóstico de una enfermedad, sobre todo si es grave, lo más difícil para un médico es afrontar la incertidumbre del futuro y la tarea de reorganizar su vida para el corto o largo plazo. Algunos intentan convivir con la impredecibilidad, haciéndola parte de su vida; otros, más estoicos, tratan de ignorarla. No es infrecuente que algunos médicos, no obstante su formación científica, recurran a argumentos sin base racional, no solo para explicar la causa de su enfermedad sino que aceptan someterse a tratamientos no probados científicamente.

La medicina es una de las profesiones más afectadas por el estrés laboral, consecuencia de un ritmo de vida acelerado, presionado por la labor hospitalaria con sobrecarga de pacientes en la consulta y guardias agotadoras, a lo que se suma la competitividad académica, la práctica privada y las obligaciones docentes. La persistencia crónica de este desajuste laboral puede provocar el llamado síndrome de burnout o desgaste profesional, caracterizado por agotamiento emocional, desmotivación, disminución de la competencia profesional con tendencia a cometer errores, menor capacidad de concentración, irritabilidad y, eventualmente, depresión. ${ }^{2}$

\section{CUANDO FUERON PACIENTES, ¿QUÉ EXPERIENCIA TUVIERON LOS MÉDICOS DE LA ATENCIÓN SANITARIA?}

El doctor Robert Klitzman, ${ }^{3}$ médico psiquiatra, luego de perder a su hermana en las Torres Gemelas el 11 de septiembre de 2001, sufrió una grave depresión que obligó a su hospitalización. Sus vivencias como paciente las publicó en el libro When doctors become patients ("Cuando los médicos se convierten en pacientes"), donde relata su experiencia y la de otros setenta pacientes médicos que entrevistó. Estos son algunos de los testimonios:
Para un endocrinólogo su mayor angustia fueron las prolongadas esperas antes de ser atendido en la consulta, por los complicados procedimientos burocráticos de la admisión. "Es curioso -decíalas palabras "paciente" y "paciencia" tienen la misma raíz latina pátior, patieris, que significa padecer, que es lo que sienten los pacientes en las salas de espera de los consultorios».

Un pediatra hospitalizado se quejaba del horario inconveniente de la ronda quirúrgica. En su caso, el cirujano que lo atendía y su séquito llegaban de madrugada estando aún medio dormido, le enfocaba con la linterna y le decía "y qué tal, cómo le va". Antes de que pudiera decir algo, el médico ya había desaparecido.

Con frecuencia, los médicos tratantes no consideraban en sus indicaciones el horario más adecuado para la administración de un medicamento. Una doctora internista recibía kayexalato, que le producía diarrea masiva a media noche, que la mantenía despierta hasta la madrugada. Tuvo que declararse en huelga para que le cambiasen el horario de administración del fármaco.

Cuando hospitalizados, los médicos se sintieron en una condición de indefensión e intimidación durante las visitas médicas, al ser objeto de tantas miradas y escuchar el cuchicheo del personal médico y paramédico.

Algunos doctores sintieron la dureza, tosquedad e imprudencia en el manejo de situaciones delicadas. Un internista quedó devastado cuando su colega, al ver la radiografía, le dijo sin más preámbulos: «Usted tiene cáncer, lo siento, no hay nada que hacer; tiene tumor por todas partes». Se lo dijo, sin siquiera explicarle las posibles implicaciones, no le ofreció aliento, simpatía o siquiera una palabra de esperanza.

A menudo, los médicos no informaban a los pacientes los efectos adversos de un tratamiento. A un joven dermatólogo recién casado no le advirtieron que la radioterapia que le aplicaron por cáncer le iba a causar esterilidad.

Para médicos y pacientes el futuro no tiene el mismo sentido. ¿Cuánto tiempo significa "largo plazo", ¿meses, años?; o "corto plazo", ¿horas, días, semanas? Un internista quedó confundido cuando 
el médico le dijo: "No creo que su linfoma recurra en el corto plazo, he visto muchos casos; no se angustie".

El doctor Miguel Kottow, profesor de bioética de la Universidad de Chile, fue internado en una clínica por padecer el síndrome de Guillain-Barré. Sus vivencias como paciente las grabó y publicó en el libro "El pa(de)ciente", donde sostiene que la medicina institucionalizada, tal como se practica, exacerba la angustia y el sentimiento de desprotección del paciente, con pérdida de toda autonomía y participación en lo que se hace sobre él. ${ }^{4}$

\section{¿CÓMO SE COMPORTAN LOS MÉDICOS TRATANTES CON SUS COLEGAS?}

Cuando un doctor se enferma y decide consultar, generalmente acude a un colega reconocido no solo por su calidad profesional, sino también por el comportamiento amable, de voz serena, que muestra interés y con el tiempo necesario para escucharle y responderle. Lamentablemente no es lo frecuente, los médicos adoptan una actitud arrogante, se sienten dueños de la verdad absoluta y no toleran opiniones discrepantes. Esta actitud afecta la relación médico-paciente.

Según el doctor Albert Jowell, ${ }^{5}$ autor del libro "Cáncer, biografía de una supervivencia", la práctica de la medicina debe basarse en la afectividad. Con frecuencia, los médicos tratantes se interesan más por la enfermedad que por el enfermo. Son más dependientes de la tecnología y menos dispuestos a tender la mano al paciente. El principal mandamiento de la atención médica debería ser: "Trata a tus pacientes como te gustaría ser tratado". En esto consiste el humanismo médico. El doctor Jowell recordaba que cuando lo llevaban al quirófano para ser operado, el camillero le preguntó de qué le iban a operar. “De un tumor mediastínico", le dijo. El camillero le contestó: "No te preocupes, yo tengo un hermano al que lo operaron de un tumor de esos y tendrías que ver cómo juega al futbol el tío, ¡no hay quien lo pare!". El doctor agradeció su comentario, y pensó: "Tengo dudas que sea verdad lo que decía, pero esos detalles se agradecen".
Por su parte, el doctor Alberto Perales ${ }^{6}$ narra el testimonio de un distinguido miembro de la Academia Nacional de Medicina, hospitalizado en una clínica de Lima por una grave enfermedad. Le contó a un colega amigo lo sucedido en la visita médica: "Esta mañana -le dijo- no me sentía bien. Los colegas me preguntaron por todos mis síntomas y por mi respuesta al tratamiento. Científicamente cumplieron su trabajo a la perfección, pero no hicieron ninguna referencia a mi situación emocional. Me preguntaron por mi cuerpo pero no por mí. Más tarde, entró al cuarto un empleado de servicio, pues se me había volcado un poco de agua. Mientras hacía la limpieza, sonriente me miró a los ojos y me preguntó cómo me sentía. Su acercamiento fue tan genuino que nos enfrascamos en una conversación cálida por varios minutos. Me dijo unas palabras de aliento y me deseó pronta mejoría. Cuando se retiró, me sentí aliviado. Mi cerebro izquierdo dudaba, el derecho reforzó su esperanza".

La doctora África Sendino,7 internista del Hospital La Paz, de Madrid, afectada por un cáncer de mama, señala que su experiencia como paciente la llevó a reflexionar acerca de lo que realmente debe ser la compasión en la atención médica. "Compasión -dice- es el sentir que interesas al médico durante el tiempo de la consulta, que te brinda una mirada acogedora, envolvente, que posibilita una total confianza. El paciente no necesita un trato ficticiamente familiar, sino únicamente sentir que nos tiene cerca para lograr nuestro deseo de recuperar la salud".

\section{¿QUÉ ACTITUDES ADOPTAN LOS MÉDICOS CUANDO ENFERMAN?}

Algunos médicos no aceptan que una dolencia interrumpa su vida profesional y reaccionan tornándose "laboradictos", obsesivos por el trabajo, tratando de ignorar su enfermedad, especialmente si es de orden mental 0 adictivo. En casos extremos recurren a los medicamentos antidepresivos 0 al alcohol. Otros médicos, en cambio, optan por medios saludables, tratando de revitalizar sus vidas, contrarrestar el estrés y aliviar el malestar psicológico, dedicando más tiempo a la familia. 
Muchos aprenden de los pacientes, a veces con una enfermedad más grave que la del médico, pero que afrontan la enfermedad con mucho más coraje. En su condición de enfermos, algunos médicos aprecian el valor de la espiritualidad, tienen tiempo para reflexionar acerca de los problemas fundamentales de la existencia, dedican más tiempo a la práctica de la religión o, habiéndola abandonado, la retoman.

\section{¿CAMBIÓ LA RELACIÓN MÉDICO-PACIENTE DESPUÉS DE SU RECUPERACIÓN?}

Después de su recuperación, y al retornar a la consulta, generalmente mejora la relación médicopaciente, con una visión más humana del prójimo enfermo. El trato es más solícito, con empatía, dedican más tiempo a escuchar, se interesan por su vida personal y familiar. Una doctora se sorprendió cuando su médico, restablecido de una enfermedad, la atendió con especial esmero; se tomó el tiempo necesario para escucharla, anotó cuidadosamente los datos en la historia clínica, fue acucioso con las instrucciones de la receta, le previno de los efectos adversos del medicamento y tomó de buena gana la sugerencia de solicitar una segunda opinión.

\section{¿CUÁN RESPONSABLE ES EL MÉDICO EN EL CUIDADO DE SU SALUD?}

En el escrito Peri iatrós ("Sobre el médico"), del Corpus hipocraticum, se lee: "Quien no tiene un cuerpo saludable no está en aptitud de curar, pues la mayoría de la gente piensa: "Si el cuidador no sabe cuidar de sí mismo ¿cómo va a ser capaz de cuidar de los demás?" ». Una expresión más concisa se encuentra en el Evangelio de San Lucas 4:23: Medice, cura te ipsum, "Médico, cúrate a ti mismo", que en el contexto de la práctica médica significa "médico cuida de ti mismo". ${ }^{8}$

El autocuidado de la salud debería enseñarse desde el pregrado, con la finalidad de preparar a los estudiantes de Medicina cómo afrontar el estrés profesional con el menor desgaste emocional. Los administradores de las instituciones sanitarias, por su parte, deberían elaborar normas de trabajo que protejan la salud física y mental del personal como garantía de una atención de calidad para la comunidad. $^{8}$

En el nuevo Código de Deontología del Consejo de Colegios Médicos de Cataluña ${ }^{9}$ se incluyen dos artículos, el 101 y 102, en los que se considera la protección y promoción de la salud de los médicos y la salvaguarda de la buena práctica. Recomiendan al médico que se sepa enfermo o tenga dificultades para ejercer con eficiencia, consultar a otro u otros colegas, para que valoren su capacidad profesional y seguir sus indicaciones. Si un médico sabe que un colega por sus condiciones de salud puede perjudicar a los pacientes tiene el deber, con la obligada discreción, de ponerlo en conocimiento del Colegio de Médicos.

La Asociación Médica Británica, ${ }^{10}$ preocupada por el descuido de los médicos por su salud, elaboró en 1995 una guía de las responsabilidades éticas de los doctores como pacientes:

- Los médicos no deben asumir la responsabilidad del diagnóstico y manejo de los problemas de su propia salud o de sus familiares cercanos.

- Es preferible que su médico tratante no sea un pariente o consocio.

- Los médicos no deben automedicarse.

- Los médicos deben aceptar la condición de paciente cuando están bajo tratamiento.

Cuando los médicos adolezcan de un problema de salud, tienen el deber ético, para sí y para sus pacientes, de recurrir al profesional competente para la evaluación de su capacidad de trabajar y seguir su consejo.

\section{CONCLUSIONES}

Los médicos y los profesionales de la salud constituyen el capital más valioso de las instituciones hospitalarias. El día a día con los pacientes los coloca en situaciones de riesgo para su salud, que deben prevenirse. Aunque gran parte de la vida de los médicos es absorbida por la labor sanitaria, es recomendable cultivar el arte de mantener el equilibrio del trabajo con otros aspectos importantes de la vida como la familia, los amigos, las aficiones y el descanso. 


\section{REFERENCIAS BIBLIOGRÁFICAS}

I. Angulo S. Los médicos en su papel de pacientes [Internet]. Madrid, España: Saned: 2011 [citado 7 jun 2015]. Disponible en: http://www.elmedicointeractivo.com/apl/emiold/informes/ informe/medpacientes.htm

2. De Pablo R. Importancia del síndrome burnout, factores determinantes y su prevención [Internet]. En: Pascual L, Monedero MJ, Tórtola D, Beneyto F, Peñarroja D, Botija P, et al., editores. Ponencias y Comunicaciones del 16 Congreso Societat Valenciana de Medicina Familiar i Comunitària; I3-14 may 2004; Altea (Alicante), España. Barcelona: Reunions i Ciència; 2004. p. 25-30 [citado 2 jul 2009]. Disponible en: www.revistafml.es/ upload/ficheros/noticias/200909/libro.pdf

3. Klitzman R. When doctors become patients. New York, USA: Oxford University Press; 2008.

4. Terra C. Cuando el médico se transforma en paciente [Internet]. Ñuñoa (Santiago), Chile: Copesa; 2014 [citado 15 feb 2014]. Disponible en: http://www.paula.cl/entrevista/cuando-el-medicose-transforma-en-paciente/

5. Jovell A J. Cáncer: biografía de una supervivencia. Barcelona, España: Planeta; 2008.

6. Perales-Cabrera A. Morir con dignidad: aspectos psiquiátricos. Boletín CSI (Lima). 1999(3I):6-7.

7. Sendino-Revuelta A, Banegas JR. El doctor como paciente. Med Clin (Barc). 2009; I33(4): I54-5.
8. Gracia-Guillén DM. Medice cura te ipsum: sobre la salud física y mental de los profesionales médicos. Labor hospitalaria. 2004(274):89-142.

9. Colegio Oficial de Médicos de Barcelona, Fundación Galatea, editores. El Programa de Atención Integral al Médico Enfermo y el control del ejercicio profesional: La experiencia del Colegio de Médicos de Barcelona [Internet]. Barcelona: Colegio Oficial de Médicos de Barcelona y Fundación Galatea; 2013 [citado 5 jun 20I5]. Disponible en: http://www.fgalatea.org/pdf/paimm.pdf

10. British Medical Association. Ethical responsibilities in treating doctors who are patients: Guidance from the BMA Medical Ethics Department. Londres, Reino Unido: BMA; 2010 [citado 27 nov 20l4]. Disponible en: http://www.gmc-uk.org/ doctorswhoarepatientsjanuary2010.pdf_62126868.pdf

\section{Correspondencia}

Dr. Pedro Albújar Baca

albujarb@yahoo.es

Conflictos de interés

El autor declara no tener conflictos de interés durante el planteamiento, ejecución de la investigación y la elaboración del artículo para su publicación.

Fecha de recepción: 19 de junio de 2015

Fecha de aceptación: 20 de julio de 2015 